\title{
LOS LÍMITES DEL HEDONISMO EN EL DISCOURS SUR LE BONHEUR DE LA METTRIE
}

\section{THE BOUNDARIES OF HEDONISM IN LA METTRIE'S DIS- COURS SUR LE BONHEUR}

\author{
Adrián Ratto ${ }^{1}$ \\ Universidad de Buenos Aires / CONICET
}

Recibido: 06-09-2017

Aceptado:12-05-2018

Resumen: El objetivo de este trabajo es demostrar que, a pesar de lo que puede parecer en un primer momento, el hedonismo que defiende La Mettrie en el Discours sur le bonheur no implica un rechazo sin más de los valores morales ni tampoco un intento de socavar los vínculos sociales. En otras palabras, se procura poner de relieve los límites de la felicidad individual en la obra del médico de Saint-Malo. Esto, por otra parte, arroja algunas luces acerca de la problemática articulación entre la filosofía, la medicina y la política en sus trabajos.

Palabras clave: La Mettrie; felicidad; virtud; placer; sociedad

\begin{abstract}
The aim of this paper is to show that, despite what may appear, the hedonism defended by La Mettrie in the Discours sur le bonheur does not imply neither a rejection of moral values nor an attempt to undermine social bonds. In other words, the text highlights the boundaries of individual happiness in the work of the doctor of Saint-Malo. This, on the other hand, sheds some light on the problematic link between philosophy, medicine and politics in La Mettrie's works.
\end{abstract}

Keywords: La Mettrie, Happiness, Virtue; Pleasure; Society.

1. Adrián Ratto (ga_ratto@yahoo.com.ar) es Doctor en Filosofía por la Universidad de Buenos Aires. Actualmente se desempeña como investigador asistente en el Consejo Nacional de Investigaciones Científicas y Técnicas (CONICET) y como docente en la Facultad de Filosofía y Letras de la Universidad de Buenos Aires. Su área específica de trabajo es la Filosofía francesa del siglo XVIII. 


\section{Introducción}

En 1748 llegaba Julien Offray de La Mettrie a la corte de Federico II de Prusia. Ese mismo año publicaría su Discours sur le bonheur como prefacio a una traducción al francés de la obra de Séneca, De vita beata, realizada por él mismo (la obra se reeditó en 1751 como un trabajo independiente, con el título de Anti-Sénèque ou Le souverain bien). Las consecuencias morales que aparentemente se desprendían del escrito provocaron la reacción no sólo de los enemigos de les philosophes, que utilizaron la obra para mostrar a la sociedad los peligros que se desprendían de esa corriente de pensamiento ${ }^{2}$, sino también de personajes cercanos al médico de Saint-Malo, como, por ejemplo, Pierre-Louis Moreau de Maupertuis o Voltaire. Maupertuis, presidente de la Academia de Ciencias de Berlín y protector de La Mettrie, publicó en 1749 un Traité de philosophie morale, para tomar distancia de la obra de su compatriota, y Voltaire en una carta del 27 de enero de 1752 al duque de Richelieu decía en alusión al autor del Discours que «existe una gran diferencia entre combatir la superstición de los hombres y romper los lazos de la sociedad y las cadenas de la virtud $\iota^{3}$. El escrito de La Mettrie era considerado, en resumen, una amenaza para la moral y los vínculos sociales ${ }^{4}$.

El objetivo de este trabajo es demostrar que, pese a lo que puede parecer en un primer momento, el hedonismo que defiende La Mettrie en el Discours no implica por parte del autor un rechazo sin más de la virtud y los lazos sociales. Esto, por otra parte, arroja algunas luces acerca del problemático vínculo entre filosofía, medicina y política en la obra de La Mettrie.

La estructura del artículo es la siguiente: en primer lugar (2), se reconstruyen las principales tesis de L'homme machine, muchas de las cuales La Mettrie retoma al redactar el Discours. A continuación (3), se

2. Louis-Mayeul Chaudon, por ejemplo, afirmaba en su Dictionnaire anti-philosophique (1767) que la locura y la ignorancia habían llevado a La Mettrie a despreciar los valores sagrados y que «fue uno de esos Filósofos que han diseminado en sus libros el germen de la sedición», en Chaudon, L.-M.: Dictionnaire anti-philosophique. Aviñon: Girard y Seguin, 1767, pp. 211, 212. En un sentido similar, el abate Sabatier de Castres colocaría algunos años después, en 1773, la obra de La Mettire entre «los escritos impíos, sediciosos y peligrosos para la sociedad", que consideraba que no podían tolerarse, en Sabatier de Castres, A.: Les trois siècles de la littérature française, ou Tableau de l'esprit de nos écrivains, depuis François I, jusqu'en 1773. París: Moutard, 1779, vol. 3, pp. 106, 107. Todas las traducciones, salvo que se indique lo contrario, son nuestras.

3. Voltaire: «Correspondance» en Voltaire: Euvres de M. Arouet de Voltaire [ed. M. Beuchot]. París: Lefèvre - Firmin Didot Frères, 1832, vol. LVI, p. 14.

4. El problema del lazo social en el siglo XVIII ha sido el tema del dossier "Se retirer du monde», dirigido por Hélène Cussac y Odile Richard-Pauchet, que se ha publicado recientemente (2016, $\mathrm{n}^{\circ}$ 48) en la revista Dix-huitième siècle.

Thémata. Revista de Filosofía No58 (2018) pp.: 13-34. 
demuestra que de este último texto no se desprende un cuestionamiento radical a la moral y la política. Finalmente (4), se examina, a la luz de (2) y (3) la problemática articulación entre filosofía, medicina y política en la obra del médico de Saint-Malo.

\section{La ética de las máquinas}

La polémica en torno al automatismo de los animales atravesó los siglos XVI y XVII. Mientras que algunos concedían a las bestias un alma y la facultad de discernir, otros las reducían a simples mecanismos, a seres pasivos que no obedecían más que a las leyes de la física. Una de las voces más destacadas de esta controversia, que se dio en el marco de la ruptura epistemológica que tuvo lugar en esa época en el terreno de la interpretación de la naturaleza, fue sin dudas la de René Descartes, quien equiparó los animales a "máquinas" en la quinta parte de su Discours de la méthode $(1637)^{5}$. El filósofo homologa las bestias y los autómatas que puede crear el hombre; sostiene, sin embargo, que éstas, por estar hechas por las manos de Dios, están «mejor ordenadas» y poseen movimientos «más admirables» que cualquier artificio ${ }^{6}$. Ahora bien, como se sabe, Descartes atribuye al cuerpo humano las mismas características que a los animales, pero distingue al hombre de las bestias en la medida en que reconoce en éste la presencia de un alma, que, por otra parte, no puede provenir de la materia ${ }^{7}$.

El interés por la medicina llevó a La Mettrie a retomar en pleno siglo XVIII esa polémica en su L'homme machine ${ }^{8}$, cuya publicación en 1747 provocaría un seísmo en la República de las letras y lo obligaría a abandonar Leiden y a buscar refugio en la corte de Federico II de Prusia, adonde llegó en 1748 por intermedio de su amigo Pierre-Louis Moreau de Maupertuis y en donde permaneció como lector y miembro de la Academia Real de Ciencias de Berlín hasta su muerte en 1751. En ese trabajo La Mettrie fue más allá de Descartes al disolver «la distinción primitiva entre hombres y animales» ${ }^{9}$. La Mettrie no rechazó la existencia del pensamien-

5. Cf. Descartes, R.: Discurso del método [introducción, traducción y notas de Mario Caimi]. Buenos Aires: Colihue, 2004, p. 97.

6. Ídem

7. Cf. Ibídem, p. 99.

8. A propósito de la polémica en torno a la naturaleza de los animales en el siècle des Lumières, puede consultarse Rosenfield, L.: Beast-Machine to Man-Machine: Animal Soul in French Letters from Descartes to La Mettrie. Oxford: Oxford University Press, 1940. Véase también el dossier "L'animal des Lumières», publicado en el vol. 42 (2010) de la revista Dix-huitième siècle y dirigido por Jacques Berchtold y Jean-Luc Guichet.

9. La Mettrie, J.-O.: L’homme-machine [introducción y notas de Paul-Laurent Assoun]. París: Gallimard, 1999, p. 175.

Thémata. Revista de Filosofía $\mathrm{N}^{\circ} 58$ (2018) pp.: 13-34. 
to en el hombre, pero lo redujo a una propiedad de la materia ${ }^{10}$. Así, según el médico de Saint-Malo, el materialismo mecanicista alcanzaba tanto a los animales como a los seres humanos ${ }^{11}$. Concluye, entonces, que todo está hecho de la misma materia y que la única diferencia es la "organización», que «el hombre es una máquina y que no hay más que una única sustancia en el universo organizada de diferentes maneras» ${ }^{12}$.

La Mettrie se esfuerza en rehabilitar, a pesar de todo, la figura de Descartes. Si bien afirma que se perdió por momentos en vagas meditaciones (a propósito del dualismo cartesiano: res cogitans y res extensa), explica que fue él quien abrió un camino en la filosofía, al ser «el primero en demostrar que los animales eran máquinas» ${ }^{13}$. Por otra parte, sostiene que la tesis de éste acerca de la existencia de «dos sustancias» no fue más que una estrategia para evitar la censura de las autoridades civiles y eclesiásticas ${ }^{14}$. Traza, de esa manera, una línea de continuidad entre los escritos de Descartes y su hombre-máquina ${ }^{15}$.

Los trabajos sobre el «placer» y la «felicidad» de La Mettrie no son textos al margen de las obras mayores sobre el hombre y el alma, sino la otra cara de la misma moneda. En efecto, en ellos se expone lo que Paul-Laurent Assoun llama «la ética de las máquinas»" ${ }^{16}$. En el Discours sur le bonheur La Mettrie explica que, puesto que existe «una única vida» -en alusión a las tesis de L'homme-machine-, el fin del hombre no puede ser otro que una «felicidad temporal $»^{17}$. La verdadera filosofía, señala, debe conducir a los

10. Ibídem, p. 207.

11. Ann Thomson cuestiona la tesis de La Mettrie acerca de la naturaleza humana. Sostiene que existe un salto en la argumentación en el momento de la presentación de la figura del «hombre-máquina» y que ésta no es en sus escritos más que una figura retórica, cf. Thomson, A.: «L'homme-machine: mythe ou métaphore?» en Dix-huitième siècle, 20, 1988, pp. 368-370.

12. La Mettrie, J.-O.: L'homme-machine, op. cit., p. 214.

13. Ibídem, p. 206.

14. Ídem.

15. Para una interpretación diferente, véase Thomson, A.: «L'homme-machine: mythe ou métaphore?», op. cit., pp. 367, 368 y 370. Thompson rechaza la filiación entre La Mettrie y Descartes. Argumenta, entre otras cosas, que La Mettrie no comparte la concepción de la materia de Descartes. Sostiene que mientras que en los escritos de Descartes la materia es mera extensión, es decir, una sustancia pasiva, en el caso de La Mettrie ésta tiene la capacidad de moverse, organizarse y pensar.

16. Cf. Assoun, P.: «Lire La Mettrie» en La Mettrie, J.-O.: L’homme-machine. París: Gallimard, 1999, pp. 97. Francine Markovits se pregunta si «demandar a las máquinas una ética no es algo absurdo», en la medida en que los autómatas no poseen el «libre arbitrio» que parece ser una condición de cualquier moral. Markovits afirma que el planteo de La Mettrie es contradictorio a los ojos de cualquier moralista, en Markovits, F.: «La Mettrie: une éthique de l'inconstance, une métaphysique de la tendresse» en Dix-huitième siècle, 35, 2003, pp. 171, 172.

17. La Mettrie, J.-O.: Discours sur le bonheur en La Mettrie, J.-O.: Euvres philosophiques

Thémata. Revista de Filosofía No58 (2018) pp.: 13-34. 
hombres hacia ella: "[la verdadera filosofía] siembra a nuestro paso las rosas y las flores y nos enseña a recogerlas». Por el contrario, sostiene, la «falsa filosofía» y la "teología» engañan a los hombres con "quimeras» y promesas de una "felicidad eterna», oscureciendo sus días y ahogando sus placeres ${ }^{18}$.

Ahora bien, ¿cómo puede el individuo alcanzar esa «felicidad temporal»? La Mettrie explica que los «órganos» del ser humano al ser afectados producen "un sentimiento que nos hace amar la vida" y que si ese sentimiento es «duradero» se denomina «felicidad» ${ }^{19}$. A partir de esto concluye que "todo lo que produce, alimenta o excita» ese sentimiento deviene «causa de la felicidad» ${ }^{20}$. La Mettrie no parece preocuparse por la naturaleza de los objetos que provocan la felicidad. Sostiene que pueden ser felices tanto los sabios, como los ignorantes; tanto los ricos, como los pobres; tanto los virtuosos como los malvados: «Lo que me persuade de lo que acabo de plantear es ver a tantos ignorantes felices» ${ }^{21}$.

No debe sorprender al lector que a la luz de estos postulados La Mettrie haya sido en su época acusado de inmoralismo, incluso entre personajes cercanos a sus ideas, como Denis Diderot y el barón d'Holbach. Éste último diría en su Système de la nature (1770) que «el autor del L’homme machine razonó sobre las costumbres como un verdadero frenético» y que, como otros ateos, «negó la distinción entre el vicio y la virtud y predicó el libertinaje» ${ }^{22}$; Denis Diderot no dudaría, por otra parte, en su Essai sur les règnes de Claude et de Néron, et sur les mœurs et les écrits de Sénèque (1782) en referirse a La Mettrie como «un hombre disoluto y sin juicio, un bufón y un adulador» ${ }^{23}$. El editor de la Encyclopédie añade que sus escritos parecen proteger el «crimen» y el «vicio» y que los «sofismas groseros» que recorren sus páginas muestran que es un escritor que «no conoce los verdaderos fundamentos de la moral (...) $»^{24}$. Diderot parece incluso ver en la

[ed. Francine Markovits]. París: Fayard, 1987, vol. 2, p. 249.

18. Ídem.

19. Ibídem, p. 239.

20. Ídem.

21. Ibídem, p. 241.

22. Holbach, P. (barón de): Système de la nature ou des lois du monde physique et du monde moral [ed. Josiane Boulad-Ayoub]. París: Fayard, 1990, t. II, p. 339.

23. Diderot, D.: Essai sur les règnes de Claude et de Néron, et sur les mœurs et les écrits de Sénèque [ed. Annette Lorenceau, prefacio de Jean Ehrard e introducción y comentarios de Jean Deprun] en Diderot, D.: Euvres complètes de Diderot [dir. Jean Fabre, Herbert Dieckmann, Jacques Proust y Jean Varloot]. París: Hermann, 1986, vol. 25, pp. 247, 248.

24. Ibídem, p. 247. Uno de los pocos defensores del autor del Discours en su época fue el marqués de Sade, quien hace decir a uno de los personajes de sus obras, Juliette: «el célebre La Mettrie tenía razón cuando decía que era necesario echarse en el lodo como los cerdos y encontrar el placer, como ellos, en el último grado de corrupción», en Sade (marqués de): Histoire

Thémata. Revista de Filosofía No58 (2018) pp.: 13-34. 
vida misma de La Mettrie la confirmación de los errores que observaba en sus trabajos. Afirma que su muerte fue una consecuencia de «la intemperancia y la locura", que recorrieron sus escritos y su vida ${ }^{25}$.

En lo que sigue se demuestra que en el Discours se pueden observar, sin embargo, una serie de límites a la acción individual, que parecen evitar el hedonismo radical que aparentemente se desprende del trabajo.

\section{Los límites de la voluptuosidad en el Discours}

En las primeras páginas del Discours sur le bonheur, que, como ya se señaló, se publicó como prefacio a una traducción al francés de la obra De vita beata de Séneca, La Mettrie ataca al estoicismo en general y a Séneca, «el más ilustre de los estoicos», en particular: «iQué anti-estoicos seremos! Ellos son filósofos tristes, severos, duros; nosotros seremos alegres, dulces complacientes» ${ }^{26}$. Al momento de reflexionar sobre las características de la felicidad, el médico francés cuestiona a esa corriente de pensamiento el hecho de "hacer abstracción del cuerpo», de no tener en cuenta los sentimientos que experimenta el individuo ${ }^{27}$. La figura del hedonista Epicuro, que elogiaría en otros trabajos, es aparentemente la contracara de esas críticas ${ }^{28}$.

Ahora bien, a pesar de que la segunda edición del texto llevó el título de Anti-Sénèque, el objetivo de La Mettrie parece ser menos el de refutar al

de Juliette, ou les Prospérités du vice en Sade (marqués de): Euvres [ed. Michel Delon, con la colaboración de Jean Deprun]. París: Gallimard, 1998, vol. 3, p. 817. La interpretación de Sade no difiere de la de los críticos, pero en este caso no se trata de un cuestionamiento, sino de un elogio. A propósito de la recepción de La Mettrie en la obra de Sade, véase Deprun, J.: «La Mettrie et l'immoralisme sadien» en Annales de Bretagne et des pays de l'Ouest, 83, 4, 1976, pp. 745-750. Hace algunas décadas Lester Crocker, en una obra bien documentada, pero polémica, atribuía el nihilismo y el inmoralismo a todos les philosophes y presentaba a La Mettrie como uno de los personajes que mejor representaba esa posición, cf. Crocker, L.: An Age of Crisis. Baltimore: Johns Hopkins University Press, 1959, p. 83.

25. Diderot, D.: op. cit., p. 248. La Mettrie murió en 1751 en Prusia como consecuencia de una indigestión tras ingerir una gran cantidad de paté de faisán con trufas en un banquete celebrado en su honor en la casa del embajador de Inglaterra, M. Tyrconnel.

26. La Mettrie, J.-O.: Discours, op. cit., p. 238.

27. Ídem.

28. En su Système d'Épicure (1750), por ejemplo, intenta, poniendo el acento en el hedonismo de Epicuro, identificarse con el filósofo griego: "he osado unir mi voz frágil a la suya [la voz de Epicuro]», en La Mettrie, J.-O.: Système d'Épicure en La Mettrie, J.-O.: Euvres philosophiques [ed. Francine Markovits]. París: Fayard, 1987, vol. 1, pp. 367, 368). André Comte-Sponville señala los límites de la filiación entre Epicuro y La Mettrie, cf. ComteSponville, A.: «La Mettrie et le "Système d'Épicure"» en Dix-huitième siècle, 24, 1992, p. 108. Sostiene, además, que la interpretación que La Mettrie realiza del filósofo griego es "parcial» y «superficial», en la medida en que se reduce a una serie de afirmaciones de carácter general

Thémata. Revista de Filosofía №58 (2018) pp.: 13-34. 
filósofo estoico, con cuyas ideas tuvo una relación, en todo caso, ambivalente [«critiquemos, condenemos a Séneca, pero admirémosle algunas veces y estimémosle siempre» ${ }^{29}$ ], que el de «aliviar a la sociedad de un peso que la oprime»: los remordimientos ${ }^{30}$. En efecto, La Mettrie, que supone una concepción pesimista del individuo [«los hombres son en general malvados» ${ }^{31}$; «máquinas mal reguladas, inclinadas hacia el mal»"; «los grillos y cadenas que recibimos al nacer» ${ }^{33}$ ], heredada de textos libertinos del siglo anterior que influyen en su obra ${ }^{34}$, se propone liberarlo del «más grande de sus enemigos», a saber, los "remordimientos», que son, explica, recuerdos angustiantes que atormentan a los individuos ${ }^{35}$. Con ese fin desarrolla dos argumentos: a) los remordimientos están apoyados en prejuicios; b) los remordimientos son inútiles. En primer lugar (a), explica que los remordimientos que inquietan a los hombres son el fruto de principios "profundamente grabados» en la cabeza de los sujetos durante la infancia, que renacen luego de un tiempo y varían de sociedad en sociedad, de tiempo en tiempo: «otra religión, otros remordimientos; otros tiempos, otras costumbres» ${ }^{36}$. A modo de ilustración menciona a Licurgo, quien, afirma, hacía ahogar a los niños y los enfermos, felicitándose por su sabiduría, y a los hombres que entregaban a sus mujeres en Esparta al primer hombre que cruzaban, siendo éstas comunes. "iCuán hija de prejuicios es la conciencia que produce remordimientos!», exclama ${ }^{37}$. Por otra parte (b), dice que los remordimientos son «inútiles» en la medida en que los hombres actúan de acuerdo a su «organización» y que, por lo tanto, no son estos capaces de evitar una mala acción a la que un individuo está

y que el conocimiento que éste tuvo de la teoría de Epicuro se produjo a partir del acceso a trabajos de segunda mano, cf. Ibídem, pp. 107, 109. A propósito de la recepción de la filosofía de Epicuro en el siglo XVIII, véase Leddy, N. y Lifschitz, A. (eds.): Epicurus in the Enlightenment. Oxford: Voltaire Foundation, 2009.

29. La Mettrie, J.-O.: Discours, op. cit., p. 293.

30. Ibídem, p. 240.

31. Ibídem, p. 251.

32. Ibídem, p. 259.

33. Ibídem, p. 263.

34. A propósito de la relación de La Mettrie con la literatura clandestina, véase Thomson, A.: «La Mettrie et la littérature clandestine» en Bloch, O. (ed.): Le Matérialisme du XVIII siècle et la littérature clandestine. París: Vrin, 1982, p. 235-244.

35. La Mettrie, J.-O.: Discours, op. cit., p. 257.

36. Ibídem, p. 258.

37. Ídem.

Thémata. Revista de Filosofía Nº58 (2018) pp.: 13-34. 
naturalmente inclinado. Concluye, entonces: «puesto que los remordimientos son un vano remedio a nuestros males (...), destruyámoslos» ${ }^{38}$.

Para el médico de Saint-Malo la moral depende de la organización natural de nuestros órganos. Rechaza los mandatos divinos o las leyes naturales y considera los vicios y las virtudes como meras «convenciones», establecidas para el funcionamiento de la sociedad, que no es tampoco natural $^{39}$. No debe sorprendernos que, a la luz de estos postulados, haya sido en su época, como ya hemos mencionado, acusado de ser un hombre inmoral y de intentar destruir los lazos sociales, en la medida en la que todo parece quedar reducido al placer individual.

Sin embargo, de la obra de La Mettrie no parece desprenderse un hedonismo sin reservas, en el que todo remitiría al placer particular sin importar la naturaleza del objeto que lo provocara. En primer lugar, La Mettrie pone un límite a los encantos que emanan de los sentidos externos. En efecto, rechaza la identificación de la felicidad con la voluptuosidad: «no pretendo hacer consistir la felicidad en la voluptuosidad $»^{40}$. Si bien reconoce, frente a la indolencia estoica, la necesidad para aquel que pueda considerarse un hombre feliz de gozar de ciertos placeres que se desprenden de los sentidos externos, sostiene que la satisfacción que se sigue de los mismos es «demasiado breve» para, por sí misma, "constituir un estado permanente como el que requiere la felicidad ${ }^{41}$. Retoma de esta manera la distinción que había realizado en las primeras páginas de la obra entre "placer» y «felicidad», en función de las diferencias con respecto a la duración de cada uno de esos estados, siendo los placeres sensitivos, «breves y vivos» y la felicidad, un sentimiento «dulce y duradero» ${ }^{42}$. La Mettrie aconseja, por lo tanto, «moderación» en el goce de los placeres, un «manejo prudente de la voluptuosidad» ${ }^{43}$.

En segundo lugar, rechaza la identificación de la felicidad con la mera posesión de bienes externos como, entre otros, la reputación y la riqueza. "La reputación, que tanto ruido hace en el mundo", explica, no hace más que turbar la imaginación de los hombres y «echarlos a correr detrás de bienes imaginarios» ${ }^{44}$. Al referirse, por ejemplo, a la reputación que emana de las letras, se pregunta en qué sentido pueden ser felices aquellos que olvidan el sentimiento que produce el organismo para sacrificar la vida a la persecución del «quimérico honor de inmortalizar las letras que componen

38. Ibídem, p. 259.

39. Ibídem, p. 252.

40. Ibídem, p. 282.

41. Ídem.

42. Ibídem, p. 239.

43. Ibídem, p. 283.

44. Ibídem, p. 271.

Thémata. Revista de Filosofía $\mathrm{N}^{\circ} 58$ (2018) pp.: 13-34. 
sus nombres» ${ }^{45}$. Tampoco la riqueza puede ser fundamento de la felicidad. Ésta, sostiene, «no puede consistir en tener caballos mensajeros, perros y todo ese montón de lacayos, cuyo peso amenaza con hundir la parte trasera de una carroza»" ${ }^{46}$. "Alejémonos de todo lo superfluo", exclama en un tono que poco después atravesaría los escritos de Jean-Jacques Rousseau ${ }^{47}$.

Finalmente, La Mettrie sostiene que los individuos no deberían ser inútiles a la sociedad, por las siguientes razones: a) ser útil a la comunidad es una de las fuentes de la felicidad, que deben perseguir los hombres: "será uno más feliz en la medida en que no viva solamente para sí mismo, sino también para su patria, su rey y en general para la humanidad» ${ }^{48}$; b) dadas "las necesidades de la vida», los hombres no pueden vivir "únicamente para sí mismos». De allí la necesidad de los individuos de actuar de acuerdo a la virtud -aun cuando ésta sea una mera convención-, ya que ella es «el sostén» de la sociedad ${ }^{49}$.

Ahora bien, aun así la filosofía de La Mettrie parece socavar las bases de la sociedad, al considerar que los lazos sociales no son naturales. Pero, el médico de Saint-Malo, bajo la influencia del pesimismo antropológico, que, como ya se señaló, hereda de los pensadores libertinos del siglo XVII, responde que la sociedad no tiene nada que temer, dado que los hombres no están en general dispuestos a escuchar a la razón. Por ese motivo, puede decir que su "filosofía no se eleva sobre las ruinas de la sociedad» ${ }^{50}$. En todo caso, parece promover, como se verá en el próximo apartado, una reforma de esa sociedad, de sus leyes y costumbres a través de un acercamiento de la política a la filosofía y la medicina.

Se desprende de la filosofía del médico-filósofo, aparentemente, un ideal, según el cual el individuo feliz sería aquel que fuera capaz de disfrutar de momentos dulces y tranquilos, evitando las inquietudes inútiles y siendo útil a la sociedad en la que vive ${ }^{51}$. Se podría, no obstante, plantear aquí una nueva objeción: ¿no podría haber individuos que alcanzaran la felicidad actuando contra la sociedad? Puede suceder, en efecto, que exista un sujeto que encuentre una felicidad orgánica en acciones contrarias a las leyes. ¿Podría la educación modificar esas inclinaciones? Todo parece indicar que

45. Ibídem, p. 272.

46. Ibídem, p. 279.

47. Ibídem, p. 280. Con respecto a la relación entre las obras de La Mettrie y Rousseau, véase Vartanian, A.: «La Mettrie and Rousseau: The Problem of Guilt in the Eighteenth Century» en British Journal for Eighteenth-Century Studies, 8, 1985, pp. 155-172.

48. La Mettrie, J.-O.: Discours, op. cit., p. 250.

49. Ibídem, pp. 252, 253.

50. Ibídem, p. 288.

51. Cf. Ibídem, pp. 288, 289.

Thémata. Revista de Filosofía $\mathrm{N}^{\circ} 58$ (2018) pp.: 13-34. 
así sería. La Mettrie explica que la educación es el único medio que puede alterar, aunque no sin esfuerzos, la disposición natural del organismo. Ahora bien, aun en ese caso, siendo la naturaleza más fuerte que la educación, las «disposiciones primitivas» podrían en cualquier momento resurgir, borrando las que el arte hubiera producido ${ }^{52}$. ¿Qué se debería hacer en ese caso? El autor de L'homme machine sostiene, tomando como ejemplo el caso de un criminal, que, si bien comprende en función de los postulados sobre los que se apoya su reflexión, que el individuo no puede actuar de otra manera, la acción no puede ser tolerada. No duda en afirmar, entonces, que se debe consultar el «interés público» y castigar al delincuente, «así como se debe encadenar a los locos, matar a los perros rabiosos y aplastar a las serpientes $\aleph^{53}$.

\section{El médico, el filósofo y el príncipe}

En L'ouvrage de Pénélope, ou Machiavel en médecine (1748), La Mettrie, quien, como se sabe, había seguido estudios sobre medicina y ejercido la profesión, denuncia -como figura en el título- el «maquiavelismo» en el terreno de la medicina ${ }^{54}$. En este trabajo, que el autor presenta como un «juego de la imaginación», critica el saber de los "falsos doctores», los errores y las lagunas en su formación ${ }^{55}$. Afirma que poseen conocimientos meramente literarios y lamenta que los médicos desdeñen saberes útiles como la anatomía, la química, la física o la cirugía ${ }^{56}$. Por otra parte, denuncia el uso que hacen de la medicina. Explica que los médicos «se detestan entre sí» y que actúan como "comerciantes», en la medida en que sólo parecen moverse en busca del «oro y la plata» ${ }^{57}$. Agrega que son individuos «viles» y que para alcanzar sus propósitos saben «seducir» y «engañar» a las personas ${ }^{58}$.

No se trata, sin embargo, explica La Mettrie, de una crítica a la medicina en general ${ }^{59}$. Es posible, dice, realizar un buen uso de la medicina,

52. Ibídem, p. 264.

53. Ibídem, p. 265.

54. Cf. La Mettrie, J.-O.: L'ouvrage de Pénélope, ou Machiavel en médecine. Berlín: s.n., 1748, vol. 1, pp. IX, XXXVI.

55. Ibídem, p. 41.

56. Como se sabe, existió en la época una fuerte disputa entre médicos y cirujanos, a propósito de los límites de sus campos de competencia. Con respecto al estado del saber medicinal en el siglo XVIII, véase French, R.: Medicine Before Science: The Business of Medicine from the Middle Ages to the Enlightenment. Cambridge: Cambridge University Press, 2003, en particular el capítulo 8: «Enlightenment, systems and science», pp. 222-259. Véase también Brockliss, L. y Jones, C.: The Medical World of Early Modern France. Oxford: Clarendon Press, 1997.

57. Cf. La Mettrie, J.-O.: L'ouvrage de Pénélope, op. cit., p. 146.

58. Ídem.

59. Cf. Ibídem, p. 36.

Thémata. Revista de Filosofía No58 (2018) pp.: 13-34. 
una práctica no maquiavélica de la misma. Ése es, precisamente, el tema de la última parte del texto, donde opone al «maquiavelismo», un "antimaquiavelismo» y presenta a los médicos «tal como deben ser» ${ }^{60}$. El «buen médico», indica, no es aquel que se ha dejado alcanzar por los "sistemas» o que es capaz de seducir a sus pacientes con floridos discursos, sino aquel que, formado en la "filosofía experimental», "ha amoblado su cabeza con hechos y observaciones» ${ }^{61}$.

Ahora bien, el arte de curar no es algo que interese a La Mettrie sólo desde el punto de vista terapéutico, sino también político. Ya en L’hommemachine había dicho que "todo se reduce al gran arte de curar» y que «el médico es el único filósofo que merece el reconocimiento de su patria» ${ }^{62}$. Pero, ¿en qué sentido podría contribuir la medicina a la política? El Discours préliminaire, que La Mettrie empieza a escribir en 1749, poco después de la publicación del Discours sur le bonheur, como introducción a sus Euvres philosophiques (1751), puede arrojar algunas luces acerca del tema.

En ese trabajo La Mettrie se propone examinar la aparentemente problemática articulación entre política y filosofía, con el fin de refutar a aquellos que ya en su época acusaban su filosofía de destruir la virtud y las bases de la sociedad: «Me propongo demostrar que la Filosofía, por opuesta que sea a la Moral y a la Religión, no puede destruir estos dos lazos de la sociedad, como de ordinario se cree, sino que sólo puede estrecharlos y fortalecerlos» ${ }^{63}$. Explica que mientras que la filosofía, como la medicina, emana de la naturaleza, la moral y la religión son fruto de la política, es decir, el resultado de convenciones. Ahora bien, a pesar de esa diferencia sostiene -no sin generar ciertas tensiones, ciertamente- que la filosofía no puede ser peligrosa para la moral y la política por las siguientes razones: a) El hecho de que la moral y la política tengan un objeto y un fin diferente al de la filosofía no implica que una deba destruir a la otra ${ }^{64}$. Por el contrario, dice, el hecho de tener naturalezas distintas hace que una no pueda actuar sobre la otra. b) Los contenidos de los tratados filosóficos están, en todo caso en un plano «ideal, metafísico», un plano desde el que «no se puede destruir ni cambiar nada a no ser hipotéticamente» ${ }^{65}$. c) Aun

60. Ídem. Cabe recordar que Federico II de Prusia, en cuya corte se encontraba La Mettrie al momento de la redacción del texto, sentía un profundo rechazo por la figura de Maquiavelo y que había escrito un Anti-Machiavel (1740), con el propósito de refutar los principios políticos del autor de $I l$ principe. El texto había sido editado por Voltaire.

61. La Mettrie, J.-O.: L'ouvrage de Pénélope, op. cit., vol. 2, p. 347.

62. La Mettrie, J.-O.: L'homme-machine, op. cit., p. 141.

63. La Mettrie, J.-O.: Discours préliminaire en La Mettrie, J.-O.: Euvres philosophiques [ed. Francine Markovits]. París: Fayard, 1987, vol. 1, p. 9.

64. Cf. Ibídem, p. 12.

65. Ibídem, p. 15.

Thémata. Revista de Filosofía Nº5 (2018) pp.: 13-34. 
cuando la filosofía llevara consigo algún peligro para la sociedad, los hombres no lograrían comprender su mensaje, dice el médico de Saint-Malo, apoyándose una vez más en su ya mencionado pesimismo antropológico: «por mucho que el materialista pruebe que el hombre no es más que una máquina el pueblo nunca lo creerá» ${ }^{66}$.

Pero, La Mettrie no se conforma con demostrar que la filosofía no constituye un peligro para la política, es decir, que «la filosofía no rompe, ni puede romper los lazos de la sociedad ${ }^{67}$. Sostiene, además, que sería deseable que «aquellos que detentan el timón del estado sean un poco filósofos» ${ }^{68}$. ¿Ahora bien, de qué tipo de filósofo se trataría? En todo caso, no se refiere La Mettrie a aquellos que se pierden en floridas y superficiales teorías metafísicas o teológicas, sino a aquellos cuyo objeto es la naturaleza. La verdadera filosofía, explica el filósofo, está sujeta a la naturaleza, la materia, y esto es algo que «tiene en común con la verdadera medicina» 69 . La medicina y la filosofía tienen el mismo objeto, se confunden ${ }^{70}$. El filósofo debe ser, en palabras de Jacques Richard, un filósofo-médico y el buen médico, un médico-filósofo ${ }^{71}$.

Pero, ¿podrían los medicamentos prescritos por el filósofo-médico o el médico-filósofo curar definitivamente los males a los que se encuentran sometidos los individuos: los verdugos internos (los remordimientos) y externos (suplicios, cadalsos, etc.)? La respuesta es negativa, dado, una vez más, el pesimismo antropológico de La Metrrie: «la tortuga no puede correr» ${ }^{72}$, dice, refiriéndose a la multitud, que, según él, «no lee libros filosóficos» ${ }^{73}$.

Ahora bien, esto último no impide que La Mettrie considere que a partir del saber del filósofo-médico o el médico-filósofo se puedan impulsar reformas políticas, vinculadas a la utilidad pública, que hagan menos desdichada la vida de los hombres. Las leyes, explica, requieren ser rectificadas y reformadas y ésa, sostiene, es una tarea de la verdadera filosofía ${ }^{74}$. Ésta se convierte en una «antorcha útil», que puede iluminar a «legisladores, jueces,

66. Ibídem, p. 20.

67. Ibídem, p. 15.

68. Ibídem, p. 42.

69. Ibídem, p. 10.

70. Cf. Ibídem, p. 60.

71. Cf. Richard, J.: «Médecine, physique et métaphysique dans les oeuvres philosophiques de La Mettrie» en Audidière, S. et al.: Matérialistes français du XVIIIe siècle. París: Presses Universitaires de France, 2006, pp. 28, 31.

72. La Mettrie, J.-O.: Discours préliminaire, p. 42.

73. Ibídem, p. 24.

74. Cf. Ibídem, p. 38.

Thémata. Revista de Filosofía №58 (2018) pp.: 13-34. 
magistrados» ${ }^{75}$ para que cometan menos actos injustos e inicuos y a los "príncipes" para que adviertan la distancia que existe entre "sus caprichos, sus tiránicos actos, sus leyes, su religión» y «la verdad, la equidad y la justicia» ${ }^{76}$.

Se podría aún hacer una objeción: ¿por qué el filósofo-médico o el médico-filósofo debería comprometerse en los asuntos de la ciudad? ¿No sería una mejor opción el alejamiento de los problemas que suelen acarrear los asuntos públicos? Como ya se dijo, La Mettrie afirma que no vivir únicamente para uno mismo, sino también para los otros, es un motivo de felicidad. En ese marco se deben leer las primeras líneas del L’homme machine, donde afirma que «no es suficiente para el sabio conocer la naturaleza y la verdad, sino que es necesario también comunicarla en favor de aquel pequeño número de personas que está en posición de comprenderla» ${ }^{77}$. Esto se repite en el Discours sur le bonheur, cuando sostiene que «el único partido digno del sabio» es actuar en función de los seres que lo rodean ${ }^{78}$. El sabio debe ser, como sostiene Kathleen Wellman, un philosophe engagé ${ }^{79}$. Se podría pensar, tal vez, que es precisamente ése el motivo que habría llevado a La Mettrie a escribir sus trabajos filosóficos, aunque él afirma en sus escritos que se trató de un mero acto de vanidad.

\section{A modo de conclusión}

Robert Mauzi en su célebre trabajo Lïdée du bonheur dans la littérature et la pensée française au XVIII siècle (1965) afirma, refiriéndose al placer en la obra de La Mettrie, que éste «sin preocuparse en ninguna medida por la sociedad y sus leyes, rechaza toda regla que lo contradice» ${ }^{80}$. Asimismo, Pierre Naville sostiene, intentando mostrar la distancia que existe entre Diderot y el barón d'Holbach con respecto a La Mettrie, que este último «invita al individuo a gozar sin preocuparse por las leyes» ${ }^{81}$. El conflicto que parece generarse entre la búsqueda de la felicidad individual

75. Ibídem, pp. 41, 42 .

76. Ibídem, p. 43. Para una interpretación diferente, véase Thomson, A.: «Le bonheur matérialiste selon La Mettrie» en Fink, B. y Stenger, G.: Ettre matérialiste à l'âge des Lumières. Hommage offert à Roland Desné. París: Presses Universitaires de France, 1999, p. 311. Thomson considera que "él [La Mettrie] no intenta conciliar su filosofía con las necesidades de la sociedad».

77. La Mettrie, J.-O.: L'homme-machine, op. cit., p. 143.

78. La Mettrie, J.-O.: Discours sur le bonheur, op. cit., p. 250.

79. Cf. Wellman, K.: La Mettrie: Medicine, Philosophy and Enlightenment. Londres: Duke University Press, 1992, p. 251.

80. Mauzi, R.: L’idée du bonheur dans la littérature et la pensée française au XVIII siècle. París: Armand Colin, 1965, p. 249.

81. Naville, P.: D’Holbach et la philosophie scientifique au XVIII siècle. París: Gallimard, 1967, p. 181.

Thémata. Revista de Filosofía Nº58 (2018) pp.: 13-34. 
y las reglas sociales en la filosofía del médico francés es aquello que, según Naville, inquieta al resto de les philosophes. La prioridad otorgada a la sensibilidad individual, entiende el autor, coloca a La Mettrie en la línea de pensamiento de personajes como Pierre Choderlos de Laclos, Nicolás Restif de la Bretonne o el marqués de Sade. En trabajos más recientes Francine Markovits afirma que la filosofía de La Mettrie se desliza hacia el «libertinaje» y Jonathan Israel, quien ha escrito la última gran suma acerca de la filosofía de la Ilustración, califica su teoría como «amoral»" ${ }^{82}$. Consideramos que estas interpretaciones simplifican la posición de La Mettrie acerca de la moral y la política. De este trabajo se desprende la necesidad de matizar este tipo de lecturas. Hemos intentado demostrar que en los escritos del médico de Saint-Malo, en particular el Discours sur le bonheur, se pueden reconocer una serie de límites a la acción individual, ya sea al evitar la identificación entre la felicidad y la voluptuosidad o los bienes externos, ya sea al procurar, no sin generar tensiones, ciertamente, no oponer la acción individual a la virtud y las leyes, llegando incluso a declarar que es necesario castigar -aun cuando comprende que el individuo no es libre al elegir el curso de su accióna aquel que viola las reglas sociales.

Por otra parte, el escrito arroja algunas luces acerca de la articulación entre filosofía, medicina y política. La misma se vuelve problemática desde el momento en el que La Mettrie afirma que la política, a diferencia de la filosofía y la medicina, no emana de la naturaleza. Sin embargo, como se ha intentado mostrar, La Mettrie pretende mantener e incluso fortalcer el vínculo entre las mismas, aconsejando a los príncipes acercarse a la filosofía-medicina y al filósofo-médico, no alejarse de los problemas de la ciudad. El sabio, dice La Mettrie, puede escribir y pensar como filósofo, pero debe actuar como un ciudadano, debe comprometerse con los asuntos públicos $^{83}$. De esta manera, La Mettrie se acerca a la posición de otros philosophes como Diderot o Voltaire, que, paradójicamente, habían criticado con vehemencia, como hemos visto, su obra.

\section{REFERENCIAS BIBLIOGRÁFICAS}

Assoun, P.-L.: «Lire La Mettrie» en La Mettrie, J.-O.: L'hommemachine. París: Gallimard, 1999, pp. 9-127.

Brockliss, L. y Jones, C.: The Medical World of Early Modern France. Oxford: Clarendon Press, 1997.

82. Markovits, F.: op. cit., p. 171; Israel, J.: Enlightenment Contested: Philosophy, Modernity, and the Emancipation of Man, 1670-1752. Nueva York: Oxford University Press, 2006, p. 810. Una interpretación similar en Stanley, S.: The French Enlightenment and the Emergence of Modern Cynicism. Cambridge: Cambridge University Press, 2012, pp. 43, 44.

83. Cf. La Mettrie, J.-O.: Discours préliminaire, op. cit., p. 18.

Thémata. Revista de Filosofía No58 (2018) pp.: 13-34. 
Chaudon, L.-M.: Dictionnaire anti-philosophique. Aviñon: Girard y Seguin, 1767.

Comte-Sponville, A.: «La Mettrie et le "Système d'Épicure"» en Dixhuitième siècle, 24, 1992, pp. 105-115.

Crocker, L.: An Age of Crisis. Baltimore: Johns Hopkins University Press, 1959.

Deprun, J.: «La Mettrie et l'immoralisme sadien» en Annales de Bretagne et des pays de l'Ouest, 83, 4, 1976, pp. 745-750.

Descartes, R.: Discurso del método [introducción, traducción y notas de Mario Caimi]. Buenos Aires: Colihue, 2004 p. 97.

Diderot, D.: Essai sur les règnes de Claude et de Néron, et sur les mœurs et les écrits de Sénèque [ed. Annette Lorenceau, prefacio de Jean Ehrard e introducción y comentarios de Jean Deprun] en Diderot, D.: $C \mathrm{Eu}$ vres complètes de Diderot [dir. Jean Fabre, Herbert Dieckmann, Jacques Proust y Jean Varloot]. París: Hermann, 1986, vol. 25.

French, R.: Medicine Before Science: The Business of Medicine from the Middle Ages to the Enlightenment. Cambridge: Cambridge University Press, 2003.

Holbach, P. (barón de): Système de la nature ou des lois du monde physique et du monde moral [ed. Josiane Boulad-Ayoub]. París: Fayard, 1990.

Israel, J.: Enlightenment Contested: Philosophy, Modernity, and the Emancipation of Man, 1670-1752. Nueva York: Oxford University Press, 2006.

La Mettrie, J.-O.: L’homme-machine [introducción y notas de PaulLaurent Assoun]. París: Gallimard, 1999.

: Discours sur le bonheur en La Mettrie, J.-O.: Euvres philosophiques [ed. Francine Markovits]. París: Fayard, 1987, vol. 2.

: Discours préliminaire en La Mettrie, J.-O.: Euvres philosophiques [ed. Francine Markovits]. París: Fayard, 1987, vol. 1.

1748, 3 vols.

: L'ouvrage de Pénélope, ou Machiavel en médecine. Berlín: s.n.,

: Système d'Épicure en La Mettrie, J.-O.: Euvres philosophiques [ed. Francine Markovits]. París: Fayard, 1987, vol. 1.

Leddy, N. y Lifschitz, A. (eds.): Epicurus in the Enlightenment. Oxford: Voltaire Foundation, 2009.

Markovits, F.: "La Mettrie: une éthique de l'inconstance, une métaphysique de la tendresse» en Dix-huitième siècle, 35, 2003, pp. 171-186.

Mauzi, R.: L’idée du bonheur dans la littérature et la pensée française au XVIII siècle. París: Armand Colin, 1965, p. 249.

Naville, P.: D'Holbach et la philosophie scientifique au XVIII e siècle. París: Gallimard, 1967, p. 181.

Richard, J.: «Médecine, physique et métaphysique dans les oeuvres 
philosophiques de La Mettrie» en Audidière, S. et al.: Matérialistes français du XVIIIe siècle. París: Presses Universitaires de France, 2006, pp. 21-43.

Rosenfield, L.: Beast-Machine to Man-Machine: Animal Soul in French Letters from Descartes to La Mettrie. Oxford: Oxford University Press, 1940.

Sabatier de Castres, A.: Les trois siècles de la littérature française, ou Tableau de l'esprit de nos écrivains, depuis François I, jusqu'en 1773. París: Moutard, 1779.

Sade (marqués de): Histoire de Juliette, ou les Prospérités du vice en Sade (marqués de): Euvres [ed. Michel Delon, con la colaboración de Jean Deprun]. París: Gallimard, 1998, vol. 3.

Stanley, S.: The French Enlightenment and the Emergence of Modern Cynicism. Cambridge: Cambridge University Press, 2012.

Thomson, A.: «L'homme-machine: mythe ou métaphore?» en Dixhuitième siècle, 20, 1988, pp. 367-376. : «La Mettrie et la littérature clandestine» en Bloch, O. (ed.): Le Matérialisme du XVIII siècle et la littérature clandestine. París: Vrin, 1982, p. 235-244.

ger, $\mathrm{G} \cdot \overline{\hat{E} \text { tre }}$ matérialiste à l'âge des Lumières. Hommage offert à Roland Desné. París: Presses Universitaires de France, 1999, pp. 299-314.

Vartanian, A.: «La Mettrie and Rousseau: The Problem of Guilt in the Eighteenth Century» en British Journal for Eighteenth-Century Studies, 8, 1985, pp. 155-172.

Voltaire: «Correspondance» en Voltaire: Euvres de M. Arouet de Voltaire [ed. M. Beuchot]. París: Lefèvre - Firmin Didot Frères, 1832, vol. LVI.

Wellman, K.: La Mettrie: Medicine, Philosophy and Enlightenment. Londres: Duke University Press, 1992. 